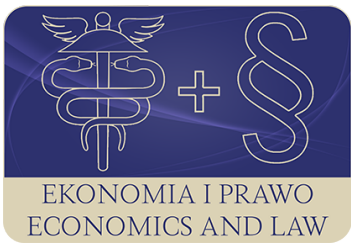

EKONOMIA I PRAWO. ECONOMICS AND LAW

Volume 15, Issue 3, September 2016

p-ISSN 1898-2255, e-ISSN 2392-1625

www.economicsandlaw.pl

EKONOMIA I PRAWO
ECONOMICS AND LAW

ORIGINAL ARTICLE

received 17.07.2015; revised 12.05.2016; accepted 30.09.2016

Citation: Florczak, W. (2016). Modelling effective legal aid system. Ekonomia i Prawo. Ecomomics andLaw, 15(3): 317-334.

doi:10.12775/EiP.2016.021.

\title{
Modelling effective legal aid system
}

\author{
WALDEMAR FLORCZAK \\ Jagiellonian University, Faculty of Management and Social Communication, Institute of Economics, \\ Finance and Management, ul. Łojasiewicza 4, 30-348 Kraków, Poland \\ $\square$ waldemar.florczak@uj.edu.pl
}

\begin{abstract}
Aim: This article presents a theoretical model that enables achievement of macroeconomic efficiency of the legal aid system by means of adjusting supply to the pre-determined demand.

Results: Main deterministic components of aggregate demand for legal aid are defined using a shift-share type framework. The knowledge of its parameters makes it possible to estimate expected demand for legal aid in response to various formulae of possible reforms of the system.

Motivation: Estimates of demand serve to compute legal aid supply that minimizes social costs of legal aid provision. This task is accomplished by means of the so called assignment problem originating the field of operational research. Providers are divided in line with their average productivities in solving appropriate legal cases and the aggregate personal costs of legal aid provision are subject to minimization.
\end{abstract}

Keywords: publicly provided goods; legal aid; supply and demand for legal aid; determinants of demand for legal aid; assignment problem; cost minimization

JEL: C29; C53; C61; H44; H50; K20; L51

\section{Introduction}

Common access to legal aid is a prerequisite of citizens' empowerment and their actual equity of opportunity. In most states belonging to the western culture there function institutionalized systems of legal aid for those in need. Yet, up to the present the problems of legal aid seem not to have been satisfactorily covered by law and economics (Winczorek, 2012, pp. 41-103). Apparently, to some extent this might be attributed to insufficient recognition of the quantitative aspects of the problem, in particular to lack of solid estimates of full demand for 
legal aid ${ }^{1}$ and of scientific procedures of balancing supply with the actual demand. Possibly, this state of affairs might have resulted in aborting many legislative initiatives in the field under consideration, as was e.g. in the case of Poland (Bojarski, 2012).

In the present article an attempt has been made to construct a model explaining demand for legal aid in order to determine adequate supply under macroeconomic efficiency. With a help of an original, shift-share like, deterministic model, main mechanisms were identified that generate aggregate demand and a decision tree was suggested that enables elaboration of variants of the total demand size in response to changes in suitable parameters of the deterministic model.

The article structure is as follows. Section 1 is devoted to general considerations on demand, supply and efficiency under particular market conditions, where payees receive the legal services free of charge. Its contents enables better understanding of the filling of section 2, where a novel decomposition of key determinants of demand for legal help has been described. Apart from the presentation of a formal model, by means of which one can estimate and forecast total demand for legal aid, some commentary follows on possible factors affecting respective components of the decomposition.

Estimates of the total demand are binding for fixing total supply of legal aid. This is, however, a necessary but insufficient condition of macroeconomic efficiency. It is only when the balancing is achieved at the lowest social costs that one can speak in terms of the efficiency. This problem constitutes subject of considerations in section 3 . Finally section 4 concludes.

\section{The current state of knowledge in the filed of demand, supply and efficiency of legal aid}

A key macroeconomic issue of legal aid is estimating expected demand on the side of payees and determining size and structure of the balancing supply. It behooves us to mention, however, that unconditional usage of the term 'demand' is a slight misuse in this context. This is so because demand and supply are inextricably linked to a third term, being prices that clear up the market.

In contrast to demand for free material and storable commodities distributed free of charge, demand for free legal aid is upper limited since the upper limit is constrained by individual needs. Consequently, the term 'demand' is in this context tantamount to the term 'need'. This clarification notwithstanding, esti-

${ }^{1}$ According to specialist nomenclature legal aid can be decomposed into the following forms of activity: legal information, legal aid, civil aid, and additional services (DPP MPiPS et al., 2013). In practice, distinguishing between these forms might be a tall order, which explains why investigations into demand and supply of legal aid do not explicitly discriminate between them (Burdziej \& Dudkiewicz, 2013; Preisert et al., 2013). Consequently, in the text to follow the term legal aid implicitly includes all the afore-mentioned forms of activity. 
mation of aggregate demand ${ }^{2}$ and determination of its main driving factors remains a crucial task.

It is not a simple research question. One cannot benefit here from data on the commercial legal advice market, as the needs of the would-be payees of the legal aid system are insufficiently satisfied by the commercial market. That is why it is necessary to carry out an adequate, national representative survey, by means of which it could be possible to estimate variants of demand with response to various decision parameters. One must, however, mention that such a survey — irrespective of its adequacy and advancement — would enable diagnosis of the present state of affairs in the field of legal aid at a given moment only. Yet, information contained in responses to suitably filtered questionnaire queries can be helpful while estimating expected demand after introducing far-reaching institutional changes to the present legal aid system, too.

There are three factors that should be regarded as crucial in the estimation. These are (Araszkiewicz, 2012, pp. 250-255; Curran \& Noone, 2007, pp. 6389; Access to Justice Taskforce, Attorney-General's Department, 2009):

- intuition of law (a poor substitute of the sense of law) of the payees;

- awareness of the access privilege;

- actual, locomotion access to legal aid.

In contrast to inferior needs, inherent to the biology of man, a need to benefit from legal advice calls for some intuition of law as a binding institution regulating weighty human relations. Yet, it is not about the sense of law but about something much narrower: things like guess/suspicion on the side of the would-be payee that a given problem could be solved in the legal course, which is a must to:

- articulate the need (affirmative response to a question on the occurrence of a legal case);

- make an attempt to solve the problem (e.g. via searching for legal advice).

Although the intuition of law seems a trivial requirement, it not so obvious that this knowledge is common, especially that a large share of the would-be payees are socially excluded. Besides, it seems reasonable to assume that a targeted mass advertising campaign could result in a significant increase in the intuition of law and awareness of the access privilege. However, while in the case of the access privilege it is possible (see further on) to elaborate procedures enabling estimation of the upper limits of demand, it remains highly unknown how this intuition can be affected by the form of an institutionalized reform of the legal aid system ${ }^{3}$.

2 From the viewpoint of terminology correctness one should use the term 'need' rather than 'demand'. Yet, in view of the problems tackled in the article these two are equivalent, and as the latter rather than the former seems to prevail in the literature, it is the term 'demand' that will be consequently used throughout the text.

${ }^{3}$ Experience of the countries with existent institutionalized systems of legal aid could be useful in this context. In particular, information on changes (increase) in demand for legal aid after the introduction of appropriate reform would be of explicit value. 
Awareness of the access privilege on the side of the payees of the legal aid system plays the first fiddle among all possible factors influencing the total demand for legal aid. Firstly, payees must be aware of this privilege to benefit from legal aid once a legal problem arises. Without such awareness they will not pay a visit to a legal clinic even if they face a legal problem. Secondly, this component can be capably stimulated by advertising campaigns, in which case one might even expect an abrupt increase in the awareness of access privilege. Thirdly, this category is inelastic downwards, meaning that once increased it cannot be fast and ready decreased because this would call for a physical oblivion of this privilege on the side of the interested parties.

The intuition of law, knowledge of the access privilege, and emergence of a legal problem are necessary but insufficient conditions to take advantage of legal aid services on the side of payees. This is so because a large share of the would-be payees are socially excluded and for them non-consultation costs also matter. That is why another factor that vitally impacts actual demand is physical/locomotion proximity of legal aid clinics, which is a function of their numerosity. Implicitly, this is the most influential agent that determines the intuition of law and the awareness of the access privilege in the long-run. It is thus of high importance to assess - even cursorily - how introduction of a reform of the legal aid system can affect total demand. Unfortunately, a reliable answer to this question can only be given post factum, although some conclusions in this respect can be drawn on the basis of an international comparative analysis if data be.

As legal aid is provided free of charge, the supply of legal aid should subordinate to the actual demand. A situation in which there was excess demand or excess supply would be by definition ineffective.

Under a simplified economic narration the supply of services for which providers get no gratification is null. Yet, there might be a vestigial provision of such services that are provided on pro publico bono basis. For obvious reasons such activities cannot satisfy the actual demand, which under mentioned circumstances is in turn very high. Consequently, the only chance to satisfy the demand for free services gives a system in which providers are paid for their socially useful work.

Balancing supply with the actual demand is a necessary but insufficient condition of macroeconomic efficiency of the legal aid system. The efficiency calls for fulfilment of some additional criteria in the course of introduction and functioning of the system. General efficiency means realizing a given target with the least possible costs or getting the most possible outcome with the fixed costs (Black, 2008, pp. 96-97). The demand generates a pool of legal problems that translate into legal advice by subject layout. This demand is in turn satisfied by specialized legal corps. Under so defined a purpose a necessary - but insufficient - condition of macroeconomic efficiency is fulfilment of the actual demand, which corresponds to the notion of outcome in the afore-mentioned definition of efficiency. 
The legal aid providers are paid for their services, which produces social costs of the system. Due to differences, both in education, professional specialization, and job experience, the providers differ with respect to their productivity, which justifies differentiation in their average salaries. In effect, legal advice - differentiated by subject and complexity — can be supplied by various providers. Finally then, the problem of efficiency boils down to an optimal in the sense of minimal public costs - division of particular legal problems to particular legal aid providers.

Apart from personal costs of legal aid provision some other non-personal costs are also incurred, such as room lease, office equipment, auxiliary personnel, etc. Inclusion of such items does not impede the outlined optimization procedure that balances legal aid supply with the actual demand and minimizes the total public costs of such provision. All of those additional costs are in the first place a function of the size of the legal corps, whereas the calculation of the costs results from technological, administration or office working standards rather than from independent economic calculation ${ }^{4}$.

\section{The methodology of the research with respect to demand for legal aid}

The methodology rests upon a shift-share framework (Florczak, 2008, pp 21-46) in which one defines main determinants affecting a phenomenon under consideration in the form of an identity. Assuming homogeneity of payees and of legal advice (one type of payee and one type of legal advice) the aggregate demand for legal aid can be expressed as follows:

$$
B P P D_{t}=L U_{t} \cdot P S_{t},
$$

where:

$B P P D_{t}$ - total demand (number of legal problems/cases) in year $t$;

$L U_{t}$ - number of people eligible for legal aid in period $t$;

$P S_{t}$ - probability (frequency) of benefiting from legal aid in period $t$.

In order to bring out key factors influencing the demand, formula (1) can be decomposed into the following parts:

$$
B P P D_{t}=L U_{t} \cdot S W_{t} \cdot P O T_{t} \cdot M R P_{t},
$$

because:

$$
B P P D_{t}=L U_{t} / 1 \cdot L U S_{1} / L U_{t} \cdot S P O T_{t} / L U S_{t} \cdot B P P D_{t} / S P O T_{t},
$$

${ }^{4}$ One can only express hope that such norms/standards are in general economically optimal/effective. 
where:

$S W_{t}$ - awareness of the access privilege: $S W_{t}=L U S_{t} / L U_{t}$ (where: $L U S_{t}$ - people with the awareness of the access privilege; $L U_{t}-$ all eligible people);

$P O T_{t}$ - need of legal aid: $P O T_{t}=S P O T_{t} / L_{U}$ (where: $S P O T_{t}$ - all cases of legal problems declared by eligible people; $L U S_{t}$ - people with the awareness of the access privilege);

$M R P_{t}$ - opportunity to satisfy the need: $M R P_{t}=B P P D_{t} / S P O T_{t}$ (where: $B P P D_{t}$ - all declared cases of legal aid by eligible people; $S P O T_{t}-$ all cases of legal problems declared by eligible people);

Decompositions (2) and (3) indicate main channels influencing the demand, each of which of different individual, ecological or decision nature. An attempt to explain the demand in a dynamic manner calls for explaining dynamics of these factors. Effective allocation of public means to the legal aid system requires continuous monitoring and forecasting of the demand. A starting point of such a task is identification and then quantification of factors influencing respective components of relationship (2). In what follows there is an analysis of relevant factors.

\subsection{Number of people eligible for legal aid ( $L U)$}

The number of people entitled to legal aid $\left(L U_{t}\right)$ is a function of exogenous entry criteria and total population: $L U_{t}=f\left(\right.$ entry criteria ${ }_{t}$, total population $\left.{ }_{t}\right)$.

Changes in these parameters result in changes in the total number of the payees of legal aid.

At the stage of operationalization there emerge numerous problems that require arbitrary and normative solutions. The following observations are of relevance here:

1. If the entry criteria are known a priori, then they determine the number of payees, whereas the supply should adjust to so delimited demand.

2. If the entry criteria are not set down discretionarily, then - under given total population - they should be selected in such a manner as to constrain the actual demand to the level corresponding to the actual supply, the latter being determined by available means. However, a problem arises which entry criteria to choose. Selecting various entry criteria one admits different social groups to legal aid, even if the budget constraint remains unchanged. That is why this variant of operationalization is more complex than the one that assumes an a priori knowledge of the entry criteria because it involves complicated and methodologically arguable comparisons of utilities of various groups of payees.

3. One may give up balancing demand and supply but this is tantamount to forgoing macroeconomic efficiency as such a solution leads to either excess demand or supply. 
4. Total number of payees should be computed on the basis of official data collected by the central statistical office. One should, however, mention that while such data might be easily available for a given criterion, a conjunction of criteria might result in big implementation problems. Namely, it should not be too arduous to determine total population below a given income threshold, just like e.g. number of single mothers. However, the latter criterion is obviously not independent of the former because a large share of single mothers have low income. Consequently, in the case of many diversified criteria, problems of apt determination of the total population entitled to the legal aid are snowballing due to threats of double (triple, quadruple, etc.) registration. One should also stress that the lower the number of entry criteria and higher their legibility, the higher is the social perception and consent to a possible reform of the system and the more facile is its monitoring. Yet, these entry criteria should be regarded as legislative parameters, preferably flexible enough to quickly clear up possible tensions between demand and supply, if need be.

5. A practical limitation for a discretionary choice of the entry criteria is whether appropriate information constraining the number of payees can be somehow deduced from a national questionnaire of the payees of the existent system. This is so because if a given criterion has not been even implicitly considered in the questionnaire, it has no operationalization value, just for want of data.

\subsection{Awareness of the access privilege $(S W)$}

This parameter seems crucial for estimation of total demand. It is inelastic downwards, probably being at the same time prone to a rapid rise, e.g due to a targeted mass media campaign. Once this awareness acquired, there will not be effective tools to lower it. Consequently, if demand rises rapidly, the only way to adjust it to the fixed supply might be narrowing the entry criteria, which obviously will not be met by a welcome social reception. This observation is of political recommendation: one should be quite reserved while stimulating the social awareness of the access privilege, at least at the initial stage of the reform. Otherwise the reform might fall prey of its own success.

In the long run, beside media and advertising publicity, the awareness of the access privilege is a function of the following factors (Gramatnikov et al., 2010; Access to Justice Taskforce, Attorney-General's Department, 2009):

a. individual features (age, education, income, gender, etc.);

b. ecological conditions (e.g. place of residence);

c. cumulated number of payees that have already benefited from legal aid;

d. number of legal aid clinics (this factor is strongly related to factor c)). 


\subsection{Need of legal aid, POT its components: SPOT, LUS and actual demand, $B P P D$}

The starting point of narration is scheme 1 (Araszkiewicz, 2012, pp. 250-255; Curran \& Noone, 2007, pp. 63-89; Tata, 2007, pp. 489-519). The scheme shows all possible ways to solve (or abort) declared legal problems (SPOT ) on the side of payees. Number of legal cases solved by legal aid providers ( $B P P D$ in formulas (2)-(3)) equals (see scheme 1; explanation of new symbols also in scheme 1):

$$
B P P D=B \cdot S L P B+D \cdot S L P B K,
$$

where:

$$
\begin{aligned}
& S P O T=A+B \cdot S L P B+C \cdot S L P K+D \cdot S L P B K, \\
& L U S=A 2+B+C 2+D .
\end{aligned}
$$

On the basis of questionnaire outcomes one is able to determine the actual demand for legal aid/advice only for investigated period. However, aptly filtered questions enable forecasting demand for legal services even after introduction of a reform. A key issue remains the awareness of access privilege and the way the reform is supposed to be introduced (no publicity versus a lot of it). One can distinguish a few variants depending on these two parameters:

1. Variant of maximum demand, in which it is assumed that due to extensive publicity all payees acquire knowledge of the access privilege. Moreover, it presumes that the future legal aid system will be typified by a dense net of legal clinics so that the payees will not bear high travelling costs. Under such conditions the demand can be estimated as follows: (see also formulas (2)-(3)):

$$
\begin{aligned}
& B P P D_{\text {max }}=A 11 \cdot S L P B T+A 12 \cdot S L P B T+B \cdot S L P B+C 11 \cdot S L P B \\
& +C 12 \cdot S L P B K+D \cdot S L P B K,
\end{aligned}
$$

whereas:

$$
\begin{aligned}
& S P O T_{\max }=A 11 \cdot S L P B T+A 12 \cdot S L P B T+A 13+A 21 \cdot S L P B T \\
& +A 22+B \cdot S L P B+C 11 \cdot S L P B+C 12 \cdot S L P B K+C 13 \cdot S L P K \\
& +C 2 \cdot S L P K+D \cdot S L P B K \\
& L U S_{\max }=A+B+C+D
\end{aligned}
$$

because all eligible people are aware of the access privilege.

A separate commentary is necessary to explain the dam failure effect that justifies the ring-fencing of parameter SLPBT (scheme 1). It seems reasonable to expect that an average number of legal problems of those that only recently have acquired knowledge of the access privilege will be transitionally higher than 
that of those that regularly benefit from legal aid, $S L P B$. The latter, in turn, ought to be higher than the number of legal problems articulated and solved free of charge by those that benefit from both legal aid and commercial advice, $S L P B K$. One then can expect the following inequality to hold:

$$
S L P B K<S L P B<S L P B T \text {. }
$$

The increased demand on the side of the new payees just made conscious of their privilege should be of transitory character, until the outstanding matters of theirs are fully cleared, whereas the next ones will be served online. Empirical verification of the afore-mentioned hypothesis consists in identifying the relationship between the number of legal problems declared by the payee and the time span the payee has been aware of the access privilege. Such a relationship should be a decreasing function of time. In the long-run a convergence takes place $S L P B T \rightarrow S L P B$, which means a short-term demand will be higher than the long-run demand due to the dam failure effect.

2. Variant of high demand and poor legal aid infrastructure (sparse net of legal aid clinics). This variant differs from the previous one with respect to the legal aid infrastructure, whereas the other parameters are the same. Under such circumstances LUS remains unchanged, just like in (9), but:

$$
\begin{aligned}
& B P P D_{\text {max' }^{\prime}}=A 11 \cdot S L P B T+B \cdot S L P B+C 11 \cdot S L P B+C 12 \cdot S L P B K \\
& +D \cdot S L P B K, \\
& S P O T_{\text {max }^{\prime}}=A 11 \cdot S L P B T+A 13+A 22+B \cdot S L P B+C 11 \cdot S L P B \\
& +C 12 \cdot S L P B K+C 13 \cdot S L P K+C 2 \cdot S L P K+D \cdot S L P B K .
\end{aligned}
$$

3 . Variants of demand lower than the maximum one seem obviously more realistic because they do not assume payees' full awareness of access privilege and nil mobility or time costs related to reaching appropriate legal aid clinic. This variant can be operationalized as follows:

$$
\begin{aligned}
& B P P D_{\text {realistic }}=w_{1} \cdot A 11 \cdot S L P B T+w_{1} \cdot w_{2} \cdot A 12 \cdot S L P B T \\
& +W_{2} \cdot A 21 \cdot S L P B T+B \cdot S L P B+w_{3} \cdot C 11 \cdot S L P B \\
& +W_{3} \cdot C 12 \cdot S L P B K+D \cdot S L P B K, \\
& S P O T_{\text {realistic }}=W_{1} \cdot A 11 \cdot S L P B T+w_{1} \cdot W_{2} \cdot A 12 \cdot S L P B T+A 13 \\
& +W_{2} \cdot A 21 \cdot S L P B T+A 22+B \cdot S L P B+w_{3} \cdot C 11 \cdot S L P B \\
& +W_{3} \cdot C 12 \cdot S L P B K+w_{3} \cdot C 13 \cdot S L P K+w_{3} \cdot C 2 \cdot S L P K+D \cdot S L P B K, \\
& L U S_{\text {realistic }}=w_{1} \cdot A 1+A 2+B+w_{3} \cdot C 1+C 2+D,
\end{aligned}
$$

where all the weights satisfy the following condition:

$$
0<w_{i}<1, i=1,2,3 \text {. }
$$


Weights $w_{1}$ and $w_{2}$ are assigned to changes (increase) in awareness of access privilege in the wake of the reform. Their differentiation follows types of payees, $A$ and $C$ in scheme l. Type $C$ payees are determined in their quest for solution to their problems since they take advantage of commercial service. Their commitment should then translate into more rapid learning of the access privilege. Consequently, one can expect the following inequality to hold:

$$
0<w_{1}<w_{3}<1 .
$$

Weight $W_{2}$ refers to the actual opportunity to get legal aid under awareness of access privilege (types Al2 and A2l in scheme 1). The assumption made in variant 1) of maximum demand could be found realistic only if legal aid providers in person paid home visits to the payees, not the other way round. In turn, in variant 2 (sparse net of legal aid clinics, $w_{2}=0$ ) an implicit assumption is present that introduction of the reform will not result in actual increase in accessibility of legal aid clinics ( $W_{2}=0$ ), which seems counterproductive. In effect, a much more realistic variant is the one, in which an increase in the number of legal aid clinics will lead to a better actual accessibility of legal services. Operationally, this means $0<w_{2}<1$, whereas the denser the net of legal aid clinics is, the closer the value of weight $w_{2}$ is to unity.

It is hardly possible to estimate the above weights on the basis of available data. One can only benefit from experience of other countries that monitored the demand for legal aid by the above-depicted criteria, before and after the introduction of a suitable reform of legal aid. Yet, a unique opportunity to assess changes in the actual awareness in response to the way a reform is supposed to be introduced (no publicity versus intentional and mass publicity) can give a pilot introduction of the reform solutions on a local scale, e.g. in two socio-economically up-close counties. Providing one knows the demand and the necessary operationalization parameters shown in scheme 1, one can adequately accomplish this task.

By the same token, one can analyze how the density of legal aid clinics affects the actual demand. Under similar socio-economic conditions present in two counties, only one new aid clinic could be settled in one of them, whereas some more in the other, all other things - such as relative number of providers, terms of serving legal aid, publicity, etc. - remaining the same.

A lot of invaluable information in the area under consideration can be collected by means of a national questionnaire in which - apart from other pertinent questions - there was one concerning the respondent's place of residence. Only then would it be possible to incorporate objective data on socio-economic conditions of a given administration unit that are highly relevant in the context of demand determinants for legal aid. This kind of information would enable estimation of individual components of identities (2) and (3) by means of cross-sectional or even multi-level econometric models. After all, it is not only individual factors (age, education, income, gender, etc.) but also 
meso- and macro-level ecological and institutional variables (local/regional wages, population density, economic inequalities, production structure, unemployment rate, etc.) that affect the demand (Gramatnikov et al., 2010; Access to Justice Taskforce, Attorney-General's Department, 2009). Besides, it would be possible to estimate the demand size by regional layout, which is of crucial practical importance to suitably befit supply in view of the fact that macro-scale equilibrium does not by itself guarantee local-scale equilibria.

\subsection{Demand under heterogeneity of payees and legal aid}

Assuming heterogeneity of payees and of legal advice the aggregate demand for legal aid could be computed with a help of the following formula (see formula (2)):

$$
B P P D_{t}=\sum_{i=1}^{K} \sum_{j=1}^{M}\left(L U_{i t} \cdot S W_{i t} \cdot P O T_{i j t} \cdot M R P_{i j t}\right),
$$

where:

symbols of variables given in formula (2);

$i=1, \ldots, K-$ number of eligible groups distinguished by appropriate criteria;

$j=1, \ldots, M-$ number of types of legal advice.

Accounting for inherent heterogeneity of payees and legal advice is obviously a more apt description of reality. Yet, on theoretical grounds it does not contribute much but, as can be deduced comparing formula (18) with (2), it yields a lot of technical problems ${ }^{5}$.

\section{The methodology of the research with respect to efficient supply of legal aid under fixed demand}

Efficient of supply of legal aid can be accomplished by means of the so called assignment problem (Wagner, 1980), which warrants minimization of aggregate costs of realization of a particular economic purpose in the framework of some constraint and boundary conditions. It is this operational research procedure that seems most apt to balance supply with the pre-determined demand for legal aid under the operationalization presented in section 3. The optimal solution is obtained using the Simplex algorithm (Wagner, 1980).

Certain modifications of the assignment problem enable incorporation of other cost problems - such as e.g. fixed or minimal proportions of legal aid

5 The scale of the possible problems illustrates the decomposition presented in scheme 1. Introduction of heterogeneous types of payees would result in the necessity to further decompose the relevant parameters into all respective types of payees. Accomplishing this goal would only be possible if there was available an appropriately extensive data base covering all the relevant operationalization items presented in the article. 
providers by type or some mark-up costs - making the whole operationalization correspond to the investigated reality. Finally, what emerges is the optimal number and structure of providers by type, which clears up the 'market' of legal aid under minimal social costs.

Let there be $R$-types of providers: $r=1, \ldots, R$ (distinguished by experience and/or professional specialization). The providers serve $M$-types of legal advice: $j=1, \ldots, M$ (the same layout as in formula (18)). Depending on their formal education, knowledge and experience they differ in their productivities that in turn depend on a given type of legal advice.

Let:

$\phi_{j r}$ - average productivity of the $r$-th provider in solving the $j$-th legal problem; it is about the number of specific legal problems a given provider can settle within a given period of time (say in a year) if they dealt only with cases of one type.

One has to note that so defined productivities do not take into account average wages of providers by type. Yet, this information is crucial since it is the sum of wages of all individual providers that makes up the aggregate costs of legal aid provision.

The assignment problem in the present context can be formalized as follows: objective function:

$$
f(N)=\sum_{r=1}^{R} \text { wage }_{r} N_{r} \rightarrow \text { min }
$$

constraint and boundary conditions:

$$
\left\{\begin{array}{c}
\sum_{r=1}^{R} \phi_{1 r} \cdot N_{r} \geq L_{1} \\
\sum_{r=1}^{R} \phi_{2 r} \cdot N_{r} \geq L_{2} \\
\cdots \\
\cdots \\
\sum_{r=1}^{R} \phi_{M r} \cdot N_{r} \geq L_{M} \\
N_{1} \geq 0 \\
\cdots \\
N_{R} \geq 0
\end{array},\right.
$$


or put differently:

$$
\left\{\begin{array}{c}
\phi_{11} N_{1}+\phi_{12} N_{2}+\phi_{13} N_{3}+\cdots+\phi_{1 R} N_{R} \geq L_{1} \\
\phi_{21} N_{1}+\phi_{22} N_{2}+\phi_{23} N_{3}+\cdots+\phi_{2 R} N_{R} \geq L_{2} \\
\cdots \\
\cdots \\
\phi_{M 1} N_{1}+\phi_{M 2} N_{2}+\phi_{M 3} N_{3}+\cdots+\phi_{M R} N_{R} \geq L_{M} \\
N_{1} \geq 0 \\
\cdots \\
N_{R} \geq 0
\end{array},\right.
$$

where:

$N_{r}$ - number of the $r$-th providers: $r=1, \ldots, R$;

$L_{j}$ - number of the $j$-th type legal advice: $j=1,2, \ldots, M$;

wage $_{r}$ - average wages of the $r$-th type provider.

Decision variable is the number of providers by type, whereas the aggregate costs of legal aid provision are subject to minimization. Data necessary to operationalize the concept are as follows:

- types of legal advice $(j=1, \ldots, M)$; typology must be in line with formula (18);

- types of providers $(r=1, \ldots, R)$;

- average wages of the providers by type;

- average productivity of the $r$-th provider in solving the $j$-th legal problem, $\phi_{j r}$.

The average wages by providers are unknown but they can be established on the basis of appropriate information from the commercial legal advice market, where wages of a given type of provider - say a barrister - can be treated as a point of reference. It is about the following relationship:

$$
\mathrm{rel}_{r}=\mathrm{sal}_{r} / \mathrm{sal}_{B},
$$

where:

$r=1, \ldots, R-$ types of providers;

$\mathrm{rel}_{r}$ - relation of average wages of the $r$-th type provider over average wages of the reference provider;

$s a l_{r}$ - average wages of the $r$-th type provider (established on the basis of commercial legal advice market);

$\mathrm{sal}_{B}$ - average wages of the reference provider.

For the reference category we get:

$$
\mathrm{rel}_{B}=\operatorname{sal}_{B} / \mathrm{sal}_{B}=1 \text {. }
$$


Relation (22) narrows the question of arbitrariness in establishing average wages of providers only to a discretionary decision concerning ${ }$ age $_{B}$ because the remaining items will be computed as follows:

$$
\text { wage }_{r}=\text { rel }_{r} \cdot \text { wage }_{B} \text {. }
$$

Basing the above calculus on market data discards any arbitrariness while assigning administrative wages to a particular provider because, once having discretionally determined wages for the reference group, the other wages will be set in an effective manner.

There remains an open question how to fix the wages of the reference group, wage $_{B}$ Apparently the following relation should hold:

$$
\text { wage }_{B} \leq \operatorname{sal}_{B},
$$

since there are no economic premises for legal aid providers to earn more than their commercial colleagues 6 . All in all, however, the question of establishing wages for the reference group must be subjected to a judgmental, political decision.

Introduction of an institutionalized system of legal aid might result in a decrease of demand for commercial advice. Consequently, the commercial agents should participate in the provision of legal aid to get compensated for the loss. Yet, following the rule of general efficiency it is advisable for the providers to be recruited from non-commercial circles of lawyers. The institutionalized system of legal aid should affect as little as possible the existent commercial market of commercial services (see footnote 5).

The key issue for the whole operationalization of the assignment problem given by formula (19)-(21) is determination of $\phi_{j r}$ productivities. To accomplish

${ }^{6}$ It appears logical to set wage $_{B}=s a l_{B}$ (which means equalizing the voucher price to the market rate) and boil down the whole reform to a voucher system, where payees would be given certain legal aid vouchers to be redeemed in the already existent private legal offices. Yet, there seems to be at least one strong economic counterargument to such a solution, to say nothing of some others (like a possible emergence of a black voucher market). Namely, under quite inelastic supply — if it to be limited to the members of the Bar only increasing demand for commercial legal advice (due to the introduction of the voucher system) is sure to activate the law of supply and demand, with a consequent rise in the charges for commercial legal advice (Tata, 2007, pp. 489-519). This is bound to happen even if the providers are obliged to charge only appointed rates for the legal aid to the voucher customers. In the short-run under fixed supply and fixed voucher rates, more demand is sure to result in higher charges to commercial customers. Finally, the providers - either aware or unaware of the original cause of this state of affairs - will lobby for a rise in voucher rates claiming that the existent ones lag far behind the market rates for similar services. Thus setting wage $_{B}=s a l_{B}$ and providing legal aid only by the members of the Bar will exert a continual pressure upon increasing commercial and voucher rates in a long-going interlinked feedback. Moreover, it is hardly possible to determine how long the afore-mentioned process might last before a final equilibrium rate has been reached. Yet, such a rate is sure to be higher than the initially fixed one. 
this task it is necessary to know the productivities by subject $(i=1, \ldots, M-$ types of problems) and by object ( $j=1, \ldots, R$ - types of providers) criteria. It is about filling in the following productivity matrix:

$$
\prod_{i j}=\left[\begin{array}{cccc}
\pi_{11} & \pi_{12} & \ldots & \pi_{1 R} \\
\pi_{21} & \pi_{22} & \ldots & \pi_{2 R} \\
\ldots & \ldots & \ldots & \ldots \\
\pi_{M 1} & \pi_{M 2} & \ldots & \pi_{M R}
\end{array}\right],
$$

where:

$\pi_{i j}$ - average productivity (expressed e.g. in hours) of serving legal advice of the $i$-th type by the $j$-the type provider.

Below follows a stylized example. Let us assume we have four types of legal advice (proper verses in matrix (26)):

- legal cases of low complexity,

- legal cases of standard complexity,

- legal cases of above standard complexity,

- legal cases of unprecedented complexity.

Let us also assume there are three types of legal aid providers (proper columns in matrix (26):

- paralegal,

- experienced lawyer,

- expert in law.

Than a stylized matrix (26) might be as follows:

$$
\hat{\prod_{i j}}=\left[\begin{array}{ccc}
0.5 & 0.5 & 0.5 \\
4.0 & 2.0 & 2.0 \\
\infty & 6.0 & 3.0 \\
\infty & 50.0 & 15.0
\end{array}\right] .
$$

The matrix aptly grasps the mains issues?:

- legal cases of low complexity (being closer to a piece of information rather than a piece of actual advice) can be settled by each provider fast and ready (here assumed 0.5 hour) but along with growing complexity there grows

7 The presented operationalization assumes that average labor intensity of a given piece of legal advice depends solely on its complexity, being independent of a given law subject. Yet, if to make an apparently more realistic assumption that the complexity differs on average also with respect to law subject, then such a modification does not add qualitatively to the analysis, making it only more bulky. E.g. let us assume that there are 5 types of legal advice, each of which with 4 stages of complexity, and finally - three types of providers (just like in the stylized example). Then, the size of matrix (27) grows fivefold, from $\Pi_{4 \times 3}$ to $\Pi_{20 \times 3}$. By the same token, introducing more differentiated types of legal aid providers would result in similar effects. 
time necessary to solve the case, too, in a different manner accordingly to a particular provider;

- some cases cannot be solved by lawyers with general knowledge and experience and that is why there are symbols of infinity ( $\infty$ ) in matrix (27).

\section{Conclusion}

The concept presented in the paper can be further extended and specified more precisely. On the demand side the extension can follow the general scheme described in formula (18), whereas on the supply side - some guidelines in the second paragraph of section 4 . All the categories and parameters used in the conceptualization, if operationalized, call for quite precise legal specifications. Yet, realization of this task is country, institutional and data specific so that it is virtually very difficult to be a priori concrete in this field. Obviously, gathering appropriate and reliable data of all the parameters needful to run relevant computations is a challenge by itself but as such it has not been tackled in the paper. The whole approach, supplemented by estimates of existent costs of non-institutionalized legal aid in Poland (Florczak, 2016, pp. 68-85), as well as rough estimates of its reform (Florczak, 2015, pp. 189-206), might outline necessary scientific steps to be taken towards making the whole system effective.

The presented model of balancing supply with the predetermined demand, including the decomposition of main components affecting the demand that enables general estimation of future demand following a specific formula of the reform introduction seems the first attempt of its kind. The very idea of the model seems applicable also in other areas where services are provided free of charge.

\section{References}

Access to Justice Taskforce, Attorney-General's Department. (2009). A Strategic Framework for Access to Justice in the Federal Civil Justice System. Retrieved 12.07.2016 form https://www.ag.gov.pl.

Araszkiewicz, M. (2012). Ekonomiczna analiza problematyki poradnictwa prawnego i obywatelskiego. In INPRIS, Bezplatne poradnictwo prawne i obywatelskie - analiza danych zastanych. Retrieved 12.07.2016 form http:// www.pozytek.gov.pl.

Black, J. (2008). Stownik ekonomii. Warszawa: PWN.

Bojarski, Ł. (2012). Przegląd projektów ustaw dotyczących systemowych rozwiązań poradnictwa prawnego. In INPRIS, Bezptatne poradnictwo prawne $i$ obywatelskie - analiza danych zastanych. Retrieved 12.06.2016 form http:// www.pozytek.gov.pl.

Burdziej, S., \& Dudkiewicz, M. (2013). Korzystający i niekorzystający z poradnictwa prawnego i obywatelskiego. Warszawa: ISP.

Curran, L., \& Noone, M. (2007). The Challenge of Defining Unmet Legal Need. Journal of Law and Social Policy, 21. 
DPP MPiPS. FUPP. INPRIS. ISP. \& ZBPO (2013). System nieodptatnego poradnictwa prawnego i obywatelskiego $w$ Polsce. Retrieved 12.06.2016 form http:// www.pozytek.gov.pl.

Florczak, W. (2008). Efektywna podaż pracy a wzrost gospodarczy. Gospodarka Narodowa, 11-12.

Florczak, W. (2015). Ile może kosztować reforma systemu pomocy prawno-obywatelskiej w Polsce. Studia Prawno-Ekonomiczne, 95.

Florczak, W. (2016). Szacunki kosztów nieformalnego systemu pomocy prawno-obywatelskiej. Wiadomości Statystyczne, 3.

Gramatnikov, M., Barendrecht, M., Laxminarayan, M., Verdonschot, J.H., Klaming, L., \& van Zeeland, C. (2010). A Handbook for Measuring the Costs and Quality of Access to Justice. Apeldoorn: Maklu.

Preisert, A, Schimanek, T., Waszak, M., \& Winiarska, A. (Eds.). (2013). Poradnictwo Prawne i Obywatelskie w Polsce. Stan obecny i wizje przysztości. Warszawa: ISP.

Tata, C. (2007). In the Interests of Clients or Commerce? Legal Aid, Supply, Demand, and 'Ethical Indeterminacy' in Criminal Defence Work. Journal of Law and Society, 34(4). doi:10.1111/j.1467-6478.2007.00402.x.

Wagner, H. (1980). Badania operacyjne. Warszawa: PWE.

Winczorek, J. (2012). Przegląd literatury na temat dostępności i korzystania z pomocy prawnej. In INPRIS, Bezptatne poradnictwo prawne i obywatelskie analiza danych zastanych. Retrieved 12.06.2016 form http://www.pozytek. gov.pl.

\section{Acknowledgements}

Author contributions: author have given approval to the final version of the article.

Funding: this research was was fully funded by a grant (2012/07/B/HS4/02994).

Supplementary information: author/authors acknowledge following people for help with the preparation of the article: dr Jan Winczorek. 


\section{Appendix}

\section{Scheme 1 .}

\section{Decomposition of all declared legal aid cases on the side of payees}

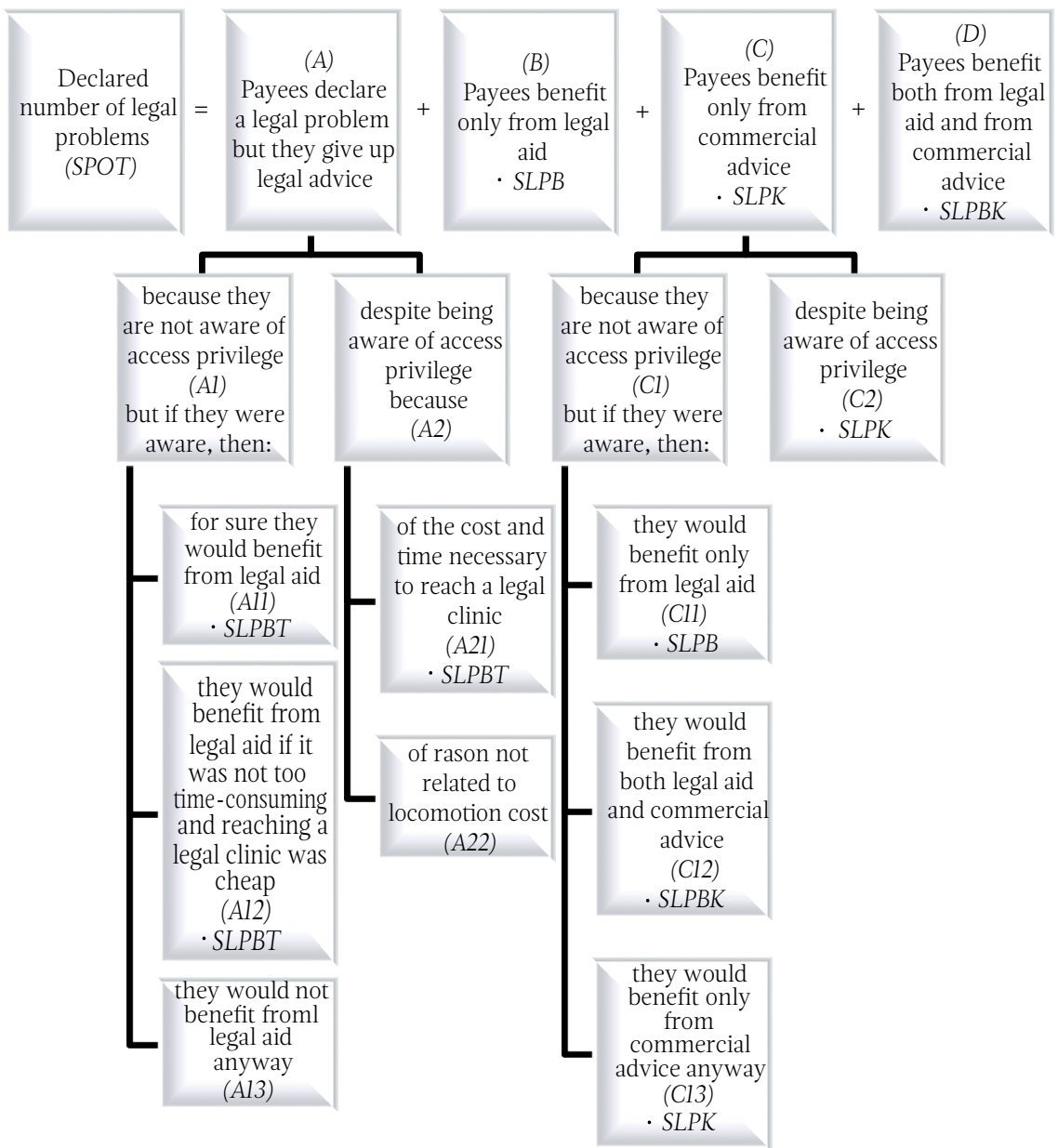

SLPB - average number of visits to a legal clinic per payee benefiting only from legal aid;

SLPBK - average number of visits to a legal clinic per payee who additionally benefits from commercial advice;

SLPBT - expected number of legal problems per payee with a newly acquired knowledge of access privilege (dam failure effect);

SLPK - average number of visits to a commercial legal office per payee (those who benefit only from commercial advice despite being entitled to legal aid).

Source: own preparation. 